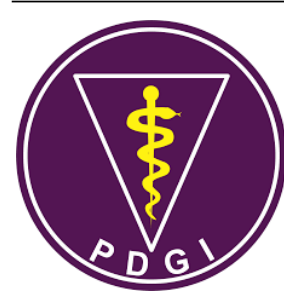

\title{
Barriers to the Implementation of Dental Insurance in Indonesia as Perceived by Primary Dentists
}

\author{
Iwan Dewanto ${ }^{1 \S}$, Sitichai Koontongkaew ${ }^{2}$, Niken Widyastuti ${ }^{1}$ \\ ${ }^{1}$ Department of Public Health Dentistry, Faculty of Medicine and Health Science, Muhammadiyah University of Yogyakarta, Indonesia \\ ${ }^{2}$ Department of Oral Biology, Faculty of Dentistry, Thammasat University, Thailand
}

Received date: August 23, 2018. Accepted date: September 25, 2018. Published date: October 19, 2018

KEYWORDS
constraint;
knowledge;
National Health Insurance;
perception

\begin{abstract}
Introduction: In 2014, the government of Indonesia launched the National Health Insurance (NHI) system. The system faced challenges in terms of its implementation because it changed the funding scheme within the pre-established health services structure. Under the new NHI system, the funding scheme for primary care providers is a capitation system; in the field of dental care, this means primary dentists received payment based on the amount number of participants enrolled within their geographical area. Objectives: The aim of this study was to describe primary dentists' perceived constraints toward the implementation of the NHI system and their level of knowledge about managed care in Yogyakarta, Indonesia. Methods: To determine dentists' perceptions about the implementation of NHI and their knowledge about managed care, we surveyed dentists in a descriptive study. Two types of questionnaire were administered to 91 dentists who work at community health centers (CHCs) in Yogyakarta, using the total population sampling technique. Result: Through the surveys, we determined that 78 dentists $(71 \%)$ perceived constraints related to capitation, 65 dentists $(72 \%)$ perceived constraints related to benefits packages, 59 dentists $(65 \%)$ perceived constraints related to workload, and 23 dentists $(25 \%)$ perceived constraints related to dental health facilities. In terms of their knowledge of managed care, 46 respondents $(50.5 \%)$ demonstrated a good knowledge of managed care, 43 respondents (47.3\%) had moderate knowledge, and 2 respondents $(2.2 \%)$ had poor knowledge. Conclusion: The constraints to managed care, as perceived by primary dentists, should be taken into account when implementing the NHI system in Yogyakarta, as these perceptions could affect the system's success.
\end{abstract}

\footnotetext{
$\S$ Corresponding Author

E-mail address: iwanjoedewanto@gmail.com (Dewanto I)
} 


\section{INTRODUCTION}

In 2014, the Indonesian government launched the National Health Insurance (NHI) system, which was also called Indonesia National Health Security (JKN). It is expected that by 2019, all citizens of Indonesia will be covered by the system. The implementation of Indonesia National Health Security (JKN) is a challenge because it demands changes to the funding scheme within health services, shifting the financial management of dental services from a fee-for-service (i.e., out-of-pocket) system to a capitation system. A capitation system is a prospective payment system in which money is provided upfront, so it requires a detailed budget pattern that can be created from a budgeting plan tailored to the concept of primary care. The reactions of Indonesian dentists to this capitation financing system have varied. Some dentists take a positive view of the capitation system, believing it will enable them to better provide highquality services with proper diagnosis and treatment and the most effective action. Dentists will prevent be equipped to reduce the incidence of pain and deliver more preventive or promotive action. The hope is that, within the capitation system, the utilization of dental treatments will be low and the cost of dental health services more efficient. However, others take a negative view of the system, believing primary dentists will simply refer patients enrolled in the NIH to specialists, freeing up their own time to serve patients who have no insurance (i.e., who will pay them more). When dentists do not provide services properly, such as easily refer patients to specialists and allowing themselves to be under-utilized, this would be disrupting the system. ${ }^{1}$

As care providers, primary dentists receive a certain amount of the money raised from capitation, as much as 2,000 Indonesian rupiahs (IDR) multiplied by the number of patients covered (usually around 8,000 to 10,000 participants). The dentists should arrange this budget to ensure they can deliver dental service to this population. However, if the dentists still deliver their service based only on curative treatments in their dental practices, this budget might be insufficient. It is hope that, within this financial scheme, primary care dentists will reduce the need for costly or curative procedures (which tend to require the most resources) by prioritizing and promoting preventative measures. ${ }^{1}$ The capitation budget pattern requires a conceptual framework adapted to the conditions of each region (through situational analysis). ${ }^{2}$ With this budget, dentists providing primary care should arrange interventions to prevent dental health problems within their populations before they arise. Primary dentists should know the condition of their population and should divide the population into those with a high risk of dental disease and those with a low risk. ${ }^{3}$

In-field observation of the capitation system has not yet been conducted by most dentists in Indonesia, and this deficiency is exacerbated by the absence of support from the Social Insurance Administration Organization (BPJS). This has some positive and some negative effects, but the overwhelming result is that Indonesian primary dentists not prepared yet to implement the capitation system. The education curriculum for Indonesian dentists, especially before 2006, does not include education about managed care or family dentistry. Therefore, the concept of a financing scheme using a prospective payment system has not been fully understood by the majority of dentists in Indonesia. The capitation system in primary care dentistry is actually based on a core health paradigm: the more participants (i.e., in a community) are healthy, the more the dentist gets wealthy. In contrast, long before NHI was implemented, most Indonesian dentists delivered their services based on a fee for service system, that based on a different paradigm: the more patients visit a dental practice, the more revenue the dentist will receive. Therefore, it is necessary to parse the discussion of the advantages and disadvantages when dentists participate as BPJS healthcare providers. ${ }^{4}$ Dentists must be consider the information related to the concept of service within the BPJS today, carefully.

The Indonesian healthcare system is characterized by a public sector and a private sector, at every level of the healthcare system. At the primary level, the public sector is decentralized and prioritized by the government (i.e., local authorities and provincial government) to ensure the availability of personnel, service facilities, equipment, and medicine to enable community health centers (CHCs) to deliver high-quality services safely. ${ }^{5}$ There are several challenges facing the delivery of oral health care to the rural population, such as a lack of personnel, poor accessibility, and a lack of affordability. In addition, the felt need of patients also plays an important role. It can be concluded that community outreach programs should be tailored to the felt need of the local population. ${ }^{6}$ Indonesian people who live in rural areas and who are less likely to report unmet dental care needs. Overall, in the present study we found that the perceived need for and utilization of dental care among Indonesians was found to be low. Moreover, the rate of unmet dental care needs is relatively high. ${ }^{7}$ The evidence indicates that rural residents have limited access to health care in general $^{8}$ and that rural areas are underserved by primary care physicians. ${ }^{9}$ In both the developing and developed world, many rural individuals must travel substantial distances for primary medical care, requiring significantly longer travel times to reach care than those required by their urban counterparts. ${ }^{10}$ Furthermore, some rural areas have a higher proportion of uninsured and individually insured residents than do urban areas. ${ }^{11}$

Despite contributing to some negative health 
behaviors, many aspects of rural social life do contribute to positive health outcomes: "Rural areas frequently have strengths including dense social networks, social ties of long duration, shared life experiences, high quality of life, and norms of self-help, and reciprocity." 12 Addressing the needs of rural areas requires building upon the positive aspects of rural life while addressing the health, public health, infrastructure, and economic needs of these areas. When determining whether an area is urban, suburban, or rural, such criteria as overall population, population density, commuting patterns, and/or distance from other settlements are used. Suburban can be defined as an area that is far from the city's core but still covers the commuter area, functioning as a place of residence of the workers in the city and manufacturing workers in the satellite city.

The Yogyakarta province consists of four districts and one municipality, which has the highest population density in the province. Based on a 2010 report by the Indonesian Central Bureau of Statistics (BPS). ${ }^{13}$ Public facilities (e.g., for education, health care, and welfare) in Yogyakarta are also considered to be the best on the island of Java. However, there is an economic gulf between the rich and the poor. As BPS data reveal, the "Gini ratio"14 (a statistical measure of the income distribution of a nation's residents, as a measure economic inequality) in Yogyakarta is the highest of all provinces on Java, meaning it has the greatest economic inequality. This fact is related to the prevalence and severity of dental caries, which tend to be more common and severe in areas with higher income inequality..$^{15}$ All CHCs in the Yogyakarta province have been contracted by the BPJS, but the number of members within each CHC varies, as it is dependent on the BPJS. The Yogyakarta district has the highest population but covers a small area, while the Gunung Kidul district has the lowest population with the largest area. Therefore, the Yogyakarta district and Sleman district are classified as urban areas, the Bantul district is classified as a suburban area, and the Gunung Kidul district are classified as rural areas. The total number of CHC dental clinics in the Yogyakarta province is 121 . CHCs are the facilities in which this research is conducted and are divided categorized based on whether they are located in urban areas (Yogyakarta and Sleman district: 40 CHCs), suburban areas (Bantul and Kulonprogo district: 42 CHCs), or rural areas (Gunung Kidul and Kulonprogo district: $41 \mathrm{CHC})$. In fact, this density problem in the Yogyakarta province has posed a major problem in Indonesia, as there is an unequal population distribution in rural and urban areas.

On paper, the implementation of National Health Insurance promises a variety of positive effects, but there are several difficulties and challenges that may arise due to the territory and population distribution of Indonesia.
However, it is not appropriate to use these challenges as a reason not to do anything. Instead, a study needs to be conducted to assess the implementation of social health insurance for primary dentists in order to better understand the real conditions within which health insurance will be provided. The following question, in particular, must be addressed: what is the perception and knowledge of primary dentists in relation to the implementation of NHI?

\section{MATERIALS AND METHODS}

This research is a cross-sectional observational study. The data used for this research is quantitative data gathered through questionnaires filled out by dentists who are primary care providers at $\mathrm{CHCs}$ in the Yogyakarta province of Indonesia. The subject of this research study is dentists who work at $\mathrm{CHC}$ dental clinics in the Yogyakarta province. Professional judgement was used to conduct proportional sampling, and $91 \mathrm{CHCs}$ were identified; the proportional sampling calculation was conducted for urban, suburban, and rural CHCs, resulting in a non-statistical sampling method. The nonstatistical sampling method is a tool by which to obtain sufficient and appropriate audit evidence in order to support the claim that the population is selected according to regulations. The main advantages of the non-statistical method are that it results in a statistically derived sample and a statistical evaluation of sampling risk. ${ }^{16}$ One of the disadvantages of the non-statistical method is that it includes the use of formal techniques to determine the size of the sample, select the sample, and evaluate the results. Proportional sampling for this research was conducted through professional judgement and can be define as follows. The Gunung Kidul and Kulonprogo districts are defined as rural areas. From these districts, 30 dentists working at $\mathrm{CHCs}$ were sampled. The Bantul and Kulonprogo districts are defined as suburban areas. From these districts, 31 dentists working at $\mathrm{CHCs}$ were sampled. The Sleman district and Yogyakarta city are defined as urban areas. From these districts, 30 dentists working at $\mathrm{CHCs}$ were sampled.

CHC dental clinics that are BPJS providers in urban, suburban, and rural areas of the Yogyakarta province were chosen by purposive sampling (i.e., convenient sampling). The chosen CHCs had to meet the following requirements: have had a cooperation agreement with BPJS at least one year, have an obvious territory based on geographical area of dental services, have complete dental equipment in accordance with the benefits package offered, be willing to cooperate, have a good administration system for collecting data.

Dentists working at $\mathrm{CHC}$ dental clinic that did not meet the above criteria were excluded. Primary care 
dentists who provide care in Yogyakarta and who implement NHI in 2014 within urban, suburban, and rural areas were surveyed using questionnaires to determine the constraints they perceive in the implementation of NHI.

\section{Research Variable}

This data was used to identify the actual problems and constraints affecting the implementation of NHI for oral health, which were divided into the following two categories: First category was dentists' perceptions of NHI implementation. This data was collected via questionnaire using a Likert17 scale, using the intervals of strong constraint (4), constraint (3), not a constraint (2), and strongly not a constraint (1). Dentists' perceptions of the following areas of implementation were measured: capitation funding (i.e., does capitation result in adequate revenue for the dentist to continue to operate?); equipment (i.e., does the dentist have a complete set of supporting equipment and materials needed to deliver their services?); benefits packages (i.e., do the eight dental treatment benefits packages determined by government correlate with the need and demand, as reflected by the disease patterns of the area?); workload (i.e., will the dentists' workloads when implementing NHI for community health services in Indonesia be manageable?). The second category was dentists' comprehension and knowledge of the NHI system and its concepts. This data was collected via questionnaire using yes-or-no questions (i.e., if the answer is correct, the score is 1 and if it is wrong, the score is 0 , and as such, this scale measurement data is nominal. Dentists' knowledge of the following implementation areas was measured: health paradigms (i.e., dentists' knowledge of the health paradigms related to the implementation of NHI for oral health); authority (i.e., dentists' knowledge of their authority in providing services according to the Health Ministry regulations, Health Ministry decree, BPJS guidelines, and Indonesia Dental Association (PB PDGI) guidelines); capitation funding (i.e., dentists' knowledge of the prospective payment system based on the concept of capitation calculation); managed care implementation (i.e., dentists' knowledge of managed care).

Validity and reliability tests used in this study were performed to test all the questionnaires. The questionnaires were tested under similar conditions to those of the CHC dental clinics in the Yogyakarta province for respondents. The validity test for this research was done by measuring the correlation between the variables or question items with a total score variable. The test of validity used a Pearson product-moment correlation coefficient, and a minimum correlation coefficient of $\geq 0.30$ was required. The reliability test in this study used the Cronbach alpha coefficient formula, in which an instrument was declared reliable if the value of the Cronbach alpha coefficient is $\geq 0.60 .{ }^{17}$ Based on Pearson product-moment correlation coefficients and Cronbach alpha coefficients, both the questionnaires used in the study were valid and reliable. Analyses of the dentist perception questionnaire and dentist knowledge questionnaire were used to describe the constraints affecting the implementation of NHI in the field of oral health in urban, suburban, and rural areas of the Yogyakarta province of Indonesia.

\section{RESULT}

The subjects of this study were dentists working at CHC dental clinics, 30 of whom worked in rural areas, 31 of whom worked in suburban areas, and 30 of whom worked in urban areas. The characteristic of most subjects age is $31-45$ years $(56 \%)$. The average length of work respondent at $\mathrm{CHC}$ is 12 years, with the shortest length of work is 2 years and the longest is 32 years (Table 1).

Table 1. Characteristic of subjects

\begin{tabular}{lcc}
\hline Categories & Number of Subjects & Percentage \\
\hline & Length of work at CHC \\
\hline $1-5$ years & 11 & $12.09 \%$ \\
$6-10$ years & 26 & $28.57 \%$ \\
$11-15$ years & 20 & $21.98 \%$ \\
$16-20$ years & 8 & $8.79 \%$ \\
$21-25$ years & 15 & $16.48 \%$ \\
26 years or more & 11 & $12.09 \%$ \\
\hline & Age of the subjects \\
\hline $31-45$ & 51 & $56 \%$ \\
$45-56$ & 49 & $44 \%$ \\
\hline
\end{tabular}

\section{Primary Dentist Perception Results}

The results of this study demonstrate that primary dentists in the Yogyakarta province perceived three aspects to be constraints to the implementation of NHI: capitation revenue, the eight dental treatment benefits packages, and workload. These three aspects are outlined in Fig. 1, Fig. 2, and Fig. 3. The factor perceived to be the most problematic constraint was capitation revenue. The results showed that the majority of dentists in the Yogyakarta province (i.e., in urban, suburban, and rural areas) have the same perception of capitation revenue, agreeing that the amount of capitation determined by the Indonesian government (rate per enrolled NHI participant is 2,000 IDR) is inadequate to carry out primary care dentistry. 
Dentists also perceive the eight dental treatment benefits packages offered to be a constraint factor, though not at as high a level as capitation revenue. The eight dental treatment benefits packages determined by the government are perceived as not suitable to meet the demand reflected by the disease patterns at their dental care clinics. A majority of dentists in the Yogyakarta province, in all three types of areas (i.e., urban, suburban, and rural) share this perception.

The required workload was also perceived to be a constraint factor for primary dentists in the Yogyakarta province. The results show that a majority of dentists in the Yogyakarta province share the perception that their workload will increase as a result of the implementation of NHI. The only aspect that dentists in the Yogyakarta province did not perceive as a constraint factor was the completeness of the equipment and materials available for delivering dental services. In rural and suburban areas the results were similar, while dentists in urban areas were less likely to view equipment availability to be a constraint factor in the implementation of NHI (Fig. 4).

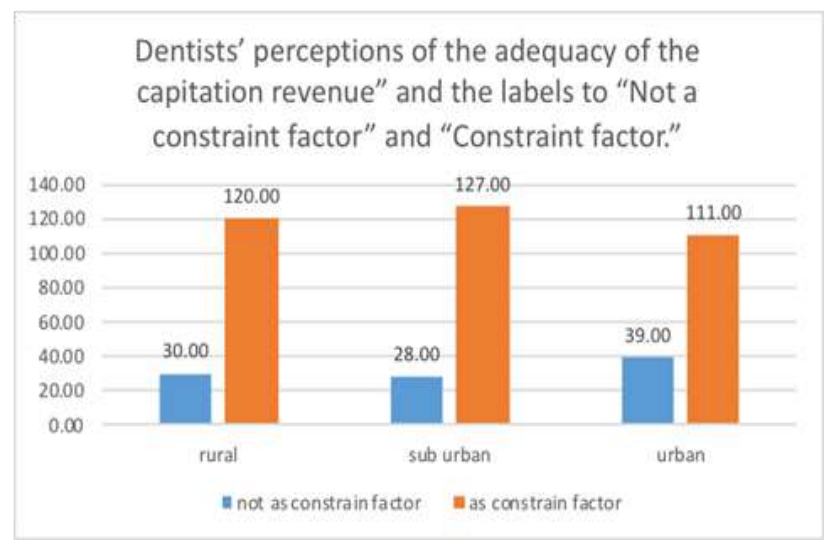

Figure 1. Perception of capitation among dentists in the Yogyakarta province.

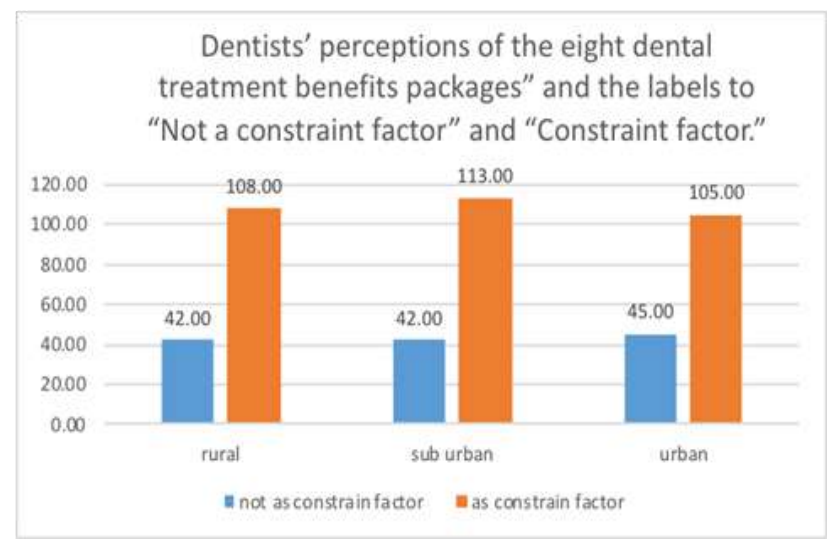

Figure 2. Perception of benefits packages among dentists in the Yogyakarta province.

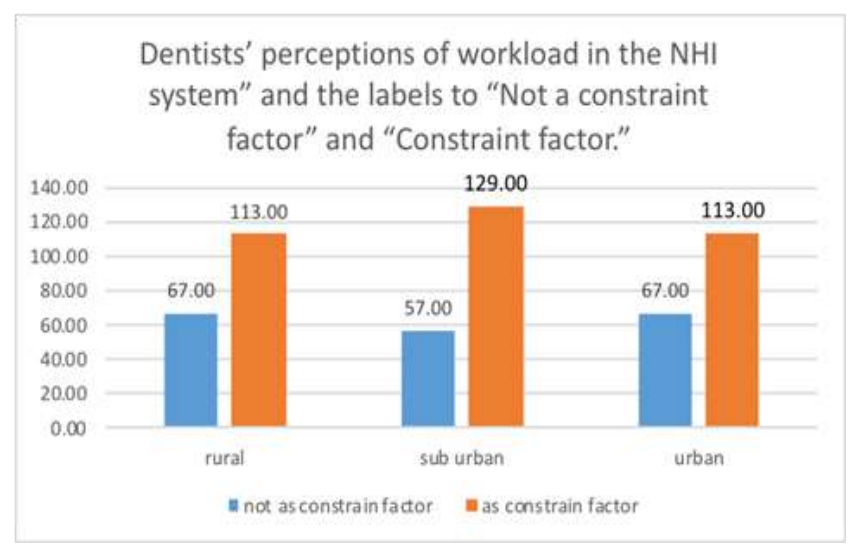

Figure 3. Perception of workload among dentists in the Yogyakarta province.

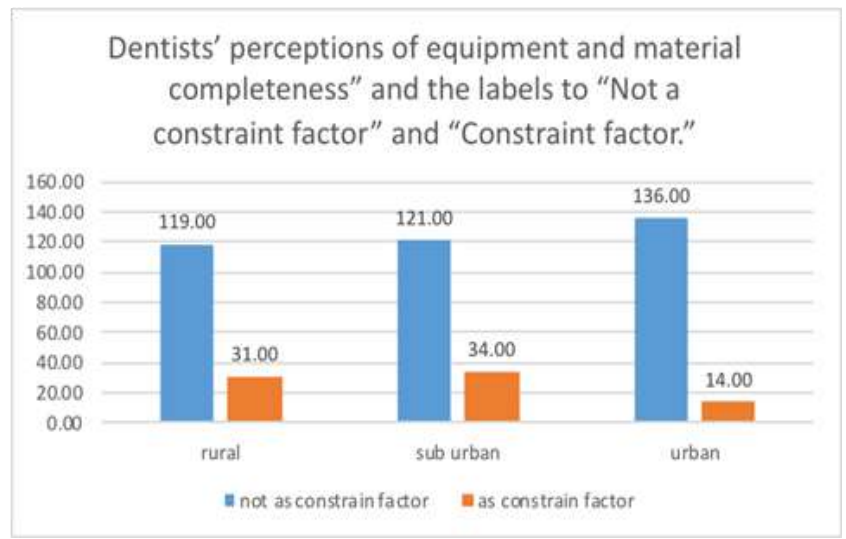

Figure 4. Perception of equipment and material completeness among dentists in the Yogyakarta province.

\section{Primary Dentist Knowledge Results}

The knowledge of primary dentists about health paradigms, authority (competency), the capitation system, and managed care was found to be satisfactory. Primary dentists in urban, suburban, and rural areas indicated that they understood the concept of NHI, with the results showing that dentists who work in $\mathrm{CHCs}$ mostly have a good knowledge of NHI and especially about its health paradigm. Despite good results overall, dentists at CHCs in suburban and urban areas were shown to be less knowledgeable about managed care concepts, scoring $62.90 \%$ and $61.67 \%$, respectively. These results were lower than those of dentists in rural areas, whose scored $70 \%$. However, primary dentists in rural areas of the Yogyakarta province had greater knowledge than their urban and suburban counterparts about health paradigms, also the capitation system.

The results showed that dentists who work in CHCs mostly have good knowledge. This is in accordance with 
Pearce, ${ }^{19}$ who stated that if medical staff are familiar with the fee-for-service financing system, they must be gain an in-depth understanding of financial management within the capitation funding system by conducting a situational analysis of the population covered by health personnel.

\section{DISCUSSION}

This study evaluate the implementation of NHI in Indonesia. We found several perceived constraints that should be considered by the Indonesian government. The results of this study showed that dentists have sufficient knowledge to implement NHI but that they perceive that some factors will inhibit their work. These perceived constraints should be addressed to ensure the smooth implementation of NHI in Indonesian primary dental care. The three perceived constraints include capitation revenue, the eight dental treatment benefits packages offered, and workload.

The amount of capitation determined by the Indonesian government (2,000 IDR) is perceived to be inadequate to properly carry out primary care dentistry within the NIH system. Primary dentists who work at $\mathrm{CHCs}$ perceive that this amount of capitation revenue is not suitable to carry out the dental services. In the capitation system, primary dentists receive up to 2,000 IDR multiplied by the total number of the participants in the program (average 10,000 participants). It is hoped that, within this financial scheme, primary care dentists will suppress the use of costly curative procedures that require the most resources by prioritizing and promoting preventative measures. ${ }^{10}$ The capitation system in primary care dentistry is based on risk and profit sharing: the more participants in the community are healthy, the more the dentist gets wealthy. ${ }^{18}$ However, this scheme does not work properly at CHCs because, as a provider of public health services, the capitation funding is not given directly to the dentist. The government instead pays such dentists using the same salary scheme of a civil servant. As such, primary dentists at $\mathrm{CHCs}$ do not have the sense of risk intended within the capitation funding scheme and are always paid monthly, even if the capitation funding is in short supply.

Most of the primary dentists in the Yogyakarta province $(71 \%)$ agreed that the benefits packages of the NHI did not meet the need and demand of the patients in the area. The eight dental treatment benefits packages determined by government were perceived not to be suitable for the need and demand reflected by the disease patterns in the areas served by the dentists. Of greatest concern, according to the results, was that premedication and other forms of treatment were not included in any of the benefits packages. Primary dentists in the Yogyakarta province encountered difficulties classifying certain treatments within the benefits packages and, as such, had to improvise when classifying treatments. Actually, this can be identified when dentists submit reports through the P-care system, the management information system which was developed by BPJS to collect information about the treatments that have been delivered in primary care. Perhaps, this system can also collects information about the delivery of health services at health facilities to evaluate dentist performance. Unfortunately, researcher did not have access for this system.

Dentist seems worries if the visited rate might be increase during the NHI program. This condition was reflected on workload result from this study. In Indonesia, the $\mathrm{CHC}$ have been subject for the implementation of national program, monitoring and reporting some of requirements, this also includes of obligation for dentist as public services. The dentists surveyed were worried that the number of patients receiving treatment would increase and that their workloads would increase accordingly. This increase in workload was perceived by primary dentists as a constraint to the implementation of NHI. However, the result in this study showed that the visit rate in rural and urban areas was not as high as the dentist had expected. The utilization rate in rural and urban areas was still below $1 \%$ of the population served, which is much lower than the national rate, calculated to be $2.03 \%$ of the population.

This study found that the dentists' perceptions of their workload were not in line with the actual visit rates in rural and urban areas. It could be seen on suburban areas which has the highest visit rates and inline with the result from the questionnaire. Primary dentists in suburban areas had accurate perceptions of the anticipate increase in their workloads. Dentists' anxiety about an increasing workload, therefore, remains a factor that can affect the implementation of NHI.

The only aspect that was not perceived to be a potential constraint was the completeness of the equipment and material at CHCs. Although it can be determined that there are differences in terms or condition of dental equipment availability in different areas. Dental equipment and materials at $\mathrm{CHCs}$ is provided by the Indonesian government, but the difference in availability depends on the budget submitted by the local government. Therefore, there is some variation between the equipment available in urban, suburban, and rural areas. Although this aspect did not appear as a perceived constraint, there were differences in dentists' perceptions about the completeness of the equipment and materials available to them. Based on this result, it can be assumed that the equipment and material at CHCs is suitable to support the implementation of NHI. 


\section{CONCLUSION}

Primary dentists' perceived constraints facing managed care should be taken into account, as these perceptions could affect the implementation of NHI in the Yogyakarta province. Based on the result of this study, it was recommended that the Indonesian government revise the benefits package policy and capitation amount currently offered (2,000 IDR). Lessons can be learned from other nations that have an established system in place, as they have already gone through the long process of learning from their failures, which is an important part of developing a system that would be effective in the long term.

\section{CONFLICT OF INTEREST}

There are no conflicts of interest.

\section{REFERENCES}

1. Thabrany H. Rasional pembayaran kapitasi. Ikatan Dokter Indonesia (IDI). 2000. Jakarta.

2. Boland P. The capitation sourcebook: a practical guide to managing at risk arrangements. California: Boland Health Care Inc. 1996.

3. Johansson V, Axtelius B, Söderfeldt B, Sampogna F, Lannerud M, Sondell K.. Financial systems' impact on dental care: a review of fee for service and capitation systems. Community Dent Health. 2007;24(1):12-20.

4. Dewanto I, Lestari NI. Panduan pelaksanaan pelayanan kesehatan gigi dan mulut dalam sistem jaminan kesehatan nasional (guide to the implementation of oral health service in a national health insurance system. 1st ed. Jakarta: PB PDGI; 2014.

5. Heywood P, Choi Y. Health system performance at the district level in Indonesia after decentralization. BMC Int Health and Human Rights. 2010;10(3):112.

6. Satinder WS, Anup N, Amaninder K, Kamaldeep K. 2014. Type of patients, disease pattern, felt needs and serves provided to patients attending Community
Dental Camps in Amritsar District. Indian J Compr Dent Care. 2014;4(2):448-51.

7. Maharani DA. Do the Indonesians receive the dental care treatment they need? a secondary analysis on self-perceived dental care need. ISRN Dent. 2012;2012:1-5.

8. Hartley D. Rural health disparities, population health, and rural culture. Am J Public Health. 2004;94(10):1675-8.

9. Kletke PR, Marder WD, Willke RJ. A projection of the primary care physician population in metropolitan and nonmetropolitan areas; Primary care research: theory and methods: AHCPR conference proceedings; Washington DC: Agency for Health Care Policy and Research; 1991. p. 261-9.

10. Van Nostrand JF, editor. Common beliefs about the rural elderly: what do national data tell us? Vital and health statistics 3 .

11. Hartley D, Quam L, Lurie N. Urban and rural differences in health insurance and access to care. Journal of Rural Health. 1994;10(2):98-108.

12. Phillips CD, McLeroy KR. Health in rural America: remembering the importance of place. Editorial. Am J Public Health. 2004;94(10):1661-3.

13. BPS-Statistics of D.I. Yogyakarta Province. Daerah Istimewa Yogyakarta in figures 2007/2008. Yogyakarta: BPS-statistics of D.I. Yogyakarta Province; 2008.

14. BPS-Statistics of Indonesia. Trends of selected socioeconomic indicators of Indonesia. Jakarta: BPSStatistics Indonesia; 2010.

15. Pattussi MP, Marcenes W, Croucher R, Sheiham A. Social deprivation, income inequality, social cohesion and dental caries in Brazilian school children. Soc Sci Med. 2001;53(7):915-25.

16. Tatiana D, Anca C. Professional judgment and reticence to apply sampling techniques. Procedia Economics and Finance. 2014;15:1253-8.

17. Singarimbun M, Sofian E. Survey research methods (Metode penelitian survei). Jakarta, Indonesia: Pustaka LP3ES Indonesia; 1989.

18. Sturm R. Effect of managed care and financing on pactice constraints and career satisfaction in primary care. J Am Board Fam Pract. 2002;15(5):367-77. 